\title{
RANCANG BANGUN ALAT UKUR JARAK BERBASIS MIKROKONTROLER AT89S51 DENGAN SENSOR ULTRASONIK
}

\author{
Aidhia Rahmi ${ }^{1}$ dan Wildian ${ }^{2}$ \\ ${ }^{1}$ Pendidikan Fisika STKIP PGRI Sumatera Barat, \\ ${ }^{2}$ Jurusan Fisika Universitas Andalas \\ Email: aidhiarahmi@yahoo.co.id \\ http://dx.doi.org/10.22202/jrfes.2015.v1i2.1404
}

\begin{abstract}
Have done the research and design of distance measuring devices with ultrasonic sensors PING based microcontroller AT89S51. With the assembly programming language. Ultrasonic sensors utilizing the properties of sound waves with a frequency of $41 \mathrm{kHz}$ beam. The working principle of the length of time for the sensor pulse (positive) high at P1.0 after doing trigger sensor. PING sensor using a pin as input and output. Distance measurements have been carried out by positioning the sensor with the object (such as water, wood and cotton). Units of measurement with a resolution centimeter is a centimeter. This tool can measure the distance between $3 \mathrm{~cm}$ to $3 \mathrm{~m}$.

Keyword: assembly language, microcontroller, trigger, sensor

ABSTRAK

Telah dilakukan penelitian dan perancangan alat ukur jarak dengan sensor ultrasonik PING berbasis mikrokontroler AT89S51. Dengan bahasa pemrograman assembly. Sensor ultrasonik memanfaatkan sifat gelombang suara dengan frekuensi pancaran $41 \mathrm{kHz}$. Prinsip kerja lamanya waktu untuk sensor pulsa (positif) high pada P1.0 setelah sensor melakukan trigger. Sensor PING menggunakan satu pin sebagai masukan dan keluaran. Telah dilakukan pengukuran jarak dengan memposisikan antara sensor dengan objek (berupa air, kayu dan kapas). Satuan pengukuran sentimeter dengan resolusi adalah satu sentimeter. Alat ini dapat mengukur jarak antara $3 \mathrm{~cm}$ sampai $3 \mathrm{~m}$.
\end{abstract}

Kata kunci: bahasa assembly, mikrokontroler, trigger, sensor

\section{PENDAHULUAN}

Ilmu pengetahuan dan teknologi berhubungan erat dengan pengukuran, oleh karena itu tidak bisa dipisahkan satu sama lainnya. Berbagai penelitian berbasis teknologi digital telah banyak dilakukan sehingga mempermudah pekerjaan manusia, salah satunya pegukuran jarak dengan menggunakan sensor ultrasonik.

Gelombang ultrasonik adalah gelombang dengan besar frekuensi diatas frekuensi gelombang suara yaitu lebih dari $20 \mathrm{KHz}$. Seperti telah disebutkan bahwa sensor ultrasonik terdiri dari rangkaian pemancar ultrasonik yang disebut transmitter dan rangkaian penerima ultrasonik yang disebut receiver. Sinyal ultrasonik yang dibangkitkan akan dipancarkan dari transmitter ultrasonik. Ketika sinyal mengenai benda penghalang, maka sinyal ini dipantulkan, dan diterima oleh 
receiver ultrasonik. Sinyal yang diterima oleh rangkaian receiver dikirimkan ke rangkaian mikrokontroler untuk selanjutnya diolah untuk menghitung jarak terhadap benda di depannya (bidang pantul). Penjalaran gelombang adalah hubungan anrata frekuensi, cepat rambat gelombang dan panjang gelombang dimana:

$$
f=\frac{c}{\lambda}
$$

Dimana $f$ : frekuensi, c; kecepatan suara di udara dan $\lambda$ : panjang gelombang.

Modul Sensor Ultrasonik (sensor PING) merupakan input utama rangkaian yang memancarkan gelombang ultrasonik setelah menerima trigger dari mikrokontroler. Setelah menerima pantulan gelombang tersebut, modul sensor PING akan mengirimkan sinyal kembali ke mikrokontroler.

\section{Mikrokontroler AT89S51}

merupakan pengembangan dari mikrokontroler MCS-51 [1]. Mikrokontroler ini biasa disebut juga dengan mikrokomputer CMOS 8 bit dengan 8 Kbyte yang dapat diprogram sampai 1000 kali pemograman. Selain itu AT89S51 juga mempunyai kapasitas RAM sebesar 128 bytes, 32 saluran I/O, dua pointer data, tiga buah timer/counter 16-bit, Programmable UART (Serial Port). Memori Flash digunakan untuk menyimpan perintah (instruksi) berstandar MCS-51, sehingga memungkinkan mikrokontroler ini bekerja sendiri tanpa diperlukan tambahan chip lainnya (single chip operation), mode operasi keeping tunggal yang tidak memerlukan eksternal memori dan memori flashnya mampu diprogram hingga seribu kali. Hal lain yang menguntungkan adalah ssstem pemogramanan menjadi lebih sederhana dan tidak memerlukan rangkaian yang rumit. Tujuan penelitian ini adalah merancang alat ukur jarak berbasis digital menggunakan sensor ultrasonic hasil pengukuran ditampilkan pada LCD

\section{METODOLOGI}

Rancang bangun alat ukur jarak dengan menggunakan sensor ultrasonik terdiri dari dua bahagian utama yaitu rancang bangun perangkat keras (hardware) dan perangkat lunak (software). Perancangan perangkat keras terdiri dari bagian sensor, rangkaian minimum untuk mikrokontroler dan rangkaian minimum untuk LCD. Untuk rancang bangun perangkat lunak menggunakan program bahasa assembly. Gambar 1 memperlihatkan blok diagram sistem pengukuran jarak dengan sensor utrasonik.

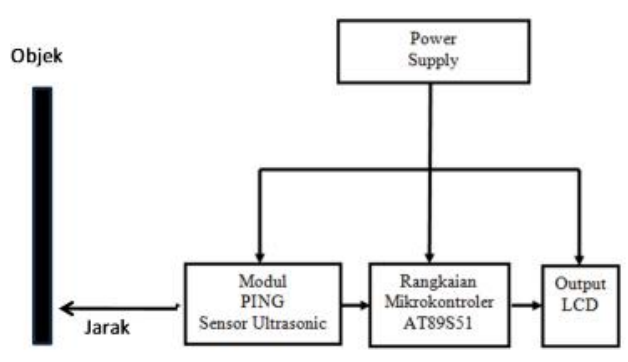

Gambar 1. Blok diagram sistem pengukuran jarak dengan sensor utrasonik

Berikut ini akan dijelaskan sistem kerja masing-masing blok diagram:

a. Rangkaian catu daya.

Rangkaian catu daya menghasilkan tiga buah tegangan +5 Volt yang masing-masing digunakan untuk mengaktifkan sensor utrasonik, rangkaian minimum LCD dan rangkaian minimum mikrokontroler. 
Untuk menghasilkan tegangan

DC dibutuhkan transformator

Stepdown yang berfungsi untuk menurunkan tegangan $220 \mathrm{~V}$ AC menjadi 7,5 V AC. Keluaran dari tegangan transformator masih berupa tegangan $\mathrm{AC}$ untuk mengubah menjadi DC maka digunakan rangkaian penyearah jembatan yang dibangun 4 dioda (D1, D2, D3 dan D4) yang saling berhubungan. Keluaran yang dihasilkan dari penyearah jembatan adalah berupa tegangan $\mathrm{DC}+7,5 \mathrm{~V}$, tegangan ini yang akan dipakai sebagai masukan pada IC regulator 7805 dengan keluaran $+5 \mathrm{~V}$. Setelah dilakukan pengukuran tegangan keluaran dari IC regulator 7805 yaitu $5,1 \mathrm{~V}$. Hasil ini disebabkan oleh beberapa faktor diantaranya karakteristik dari tiap-tiap komponen yang digunakan tidak murni dan tegangan jala-jala listrik tidak stabil.

\section{b. Rangkaian mirokontroler}

Rangkaian mirokontroler ini merupakan pusat pengolahan data dari pusat pegendali alat. Didalam rangkaian mikrokontroler ini terdapat empat buah port yang digunakan untuk menampung masukan atau keluaran data dan terhubung langsung dengan rangkaian pengendali lainnya. Rangkaian ini tersusun atas osilator kristal $12 \mathrm{MHz}$ yang berfungsi untuk membangkitkan pulsa internal dan dua kapasitor $33 \mathrm{pF}$ yang berfungsi untuk menstabilkan frekuensi. Sedangkan kapsitor 10 F, $16 \mathrm{~V}$ dan resistor $6,2 \mathrm{~K}$ pada kaki 9 berfungsi untuk rangkaian reset sebelum program yang terdapat pada mikrokontroler dijalankan.

Mikrokontroler AT89S51 memiliki fitur [5] :
1. Sebuah CPU (Central Processing Unit ) 8 Bit.

2. 128 byte RAM ( Random Acces

Memory ) internal.

3. Empat buah port I/O, yang masing-masing terdiri dari 8 bit

4. Osilator internal dan rangkaian pewaktu.

5. Dua buah timer/counter 16 bit

6. Lima buah jalur interupsi ( 2 buah interupsi eksternal dan 3 interupsi internal).

7. Sebuah port serial dengan full duplex UART (Universal Asynchronous Receive Transmitter).

8. Mampu melaksanakan proses perkalian, pembagian, dan Boolean.

9. EPROM yang besarnya 8 Kbyte untuk memori program.

c. Rangkaian sensor ultrasonik Sensor PING ))) mendeteksi jarak objek dengan cara memancarkan gelombang ultrasonik $(40 \mathrm{kHz})$ selama $\mathrm{t}_{\text {BURST }} \quad\left(\begin{array}{ll}200 & \mathrm{~s}) \quad \text { kemudian }\end{array}\right.$ mendeteksi pantulnya. Sensor PING))) memancarkan gelombang ultrasonik sesuai dengan kontrol dari mikrokontroler pengendali pulsa.

Gelombang ultrasonik ini melalui udara dengan kecepatan 344 $\mathrm{m} / \mathrm{s}$ dan mengenai obyek dan mamantulkan kembali ke sensor. PING))) menggunakan pulsa keluaran high pada pin SIG setelah memancarkan gelombang ultrasonik dan setelah gelombang mendeteksi objek yang akan di ukur. PING))) akan membuat keluaran low pada pin SIG [1]. Lebar pulsa high akan sesuai dengan lamanya waktu tempuh gelombang ultrasonik. Port 1.0 digunakan sebagai masukan dan keluaran. Gambar 2. Pengiriman pulsa pada sensor Ping))) ultrasonik. 


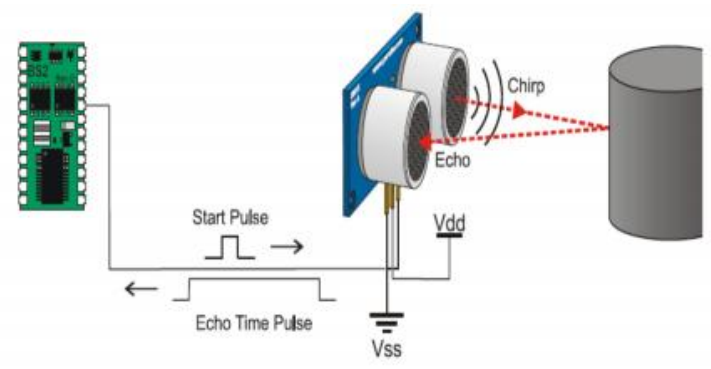

Gambar 2. Sensor Ping))) ultrasonic

Oleh karena itu harus diperhatikan saat yang tepat untuk mengatur port mikrokontroler sebagai masukan setelah mengeluarkan pulsa trigger. Gambar 3 mengilustrasikan cara kerja sensor PING))) ultrasonik. Gambar 3 mengilustrasikan cara kerja sensor PING))) ultrasonik.

Lebar pulsa High (tIN) akan sesuai dengan lama waktu tempuh gelombang ultrasonik untuk 2x jarak ukur dengan obyek. Maka jarak yang diukur adalah

Jarak yang diukur $=\frac{t_{I N} s \times 344 \mathrm{~m} / \mathrm{s}}{2}$

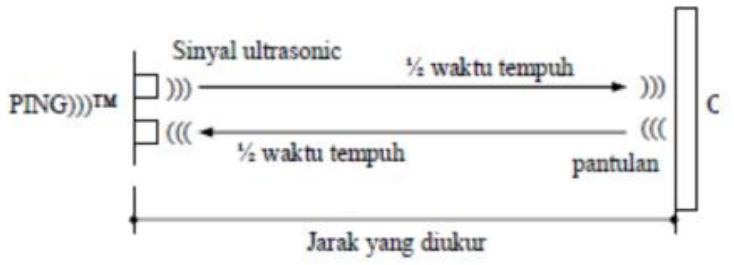

Gambar 3. Illustrasi cara kerja sensor Ping)))

\section{d. Rangkaian Penampil LCD}

Rangkaian LCD ini berguna untuk menampilkan hasil pengukuran jarak yang telah didapat dari sensor ultrasonik. Dalam perancangan alat ini pin LCD yang digunakan 4 pin data bagian MSM saja, untuk menghemat port pada mikrokontroler sehingga port yang tersisa dapat digunakan untuk keperluan lainnya. Pin no 3 LCD dihubungkan ke VR 1 $\mathrm{K}$ yang berguna untuk mengatur tampilan kontras pada LCD [4]. Backlight pada LCD memerlukan tegangan 4,3 V sehingga untuk menurunkan tegangan sebesar $5,1 \mathrm{~V}$ dari catu daya maka perlu ditambahkan dioda 1N4002 sebelum tegangan dihubungkan ke pin LCD.

Rangkaian display dipakai sebagai aksi tampilan data dengan menggunakan modul LCD M1632. Data masukan 8 bit paralel yang didapat dari port 2, sedangakan untuk kontrol dihubungkan dengan P3.4 dan P3.5 AT89S51. Semua proses dilakukan dengan pengontrolan dan format data yang diatur oleh program pada mikrokontroler.

e. Rancang bangun perangkat lunak.

Untuk perancangan perangkat lunak disini menggunakan bahasa assembly, setelah program ditulis program di konversikan ke dalam format file hex atau biner. File hex ini akan di download ke dalam mikrokontroler dengan menggunakan download ke dalam mikrokoktroler menggunakan downloader atau dengan kabel ISP untuk produk keluaran ATMEL seri 4.

Hasil pengukuran terhadap kemampuan sensor dalam mengukur jarak dengan meletakkan sensor di depan objek, dengan memvariasikan jarak dengan meletakkan sensor di depan objek yang diukur dan juga variasi antara jenis objek (kayu, kapas dan permukaan air) yang di indra oleh sensor, pengujian dilakukan sebanyak 30 kali. 


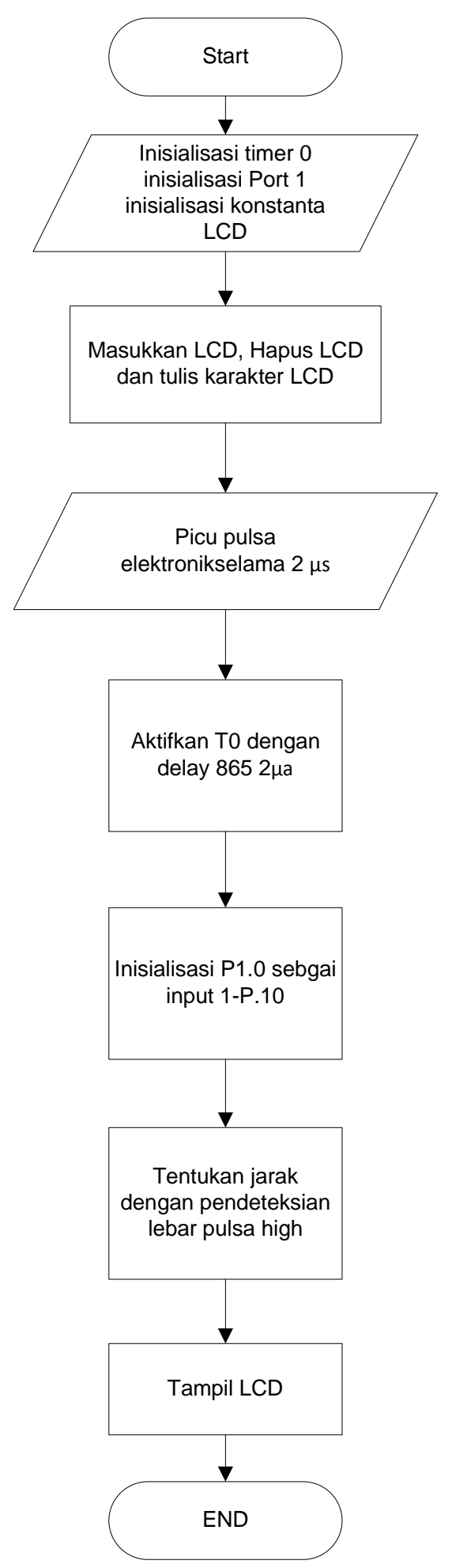

Gambar. 4 Flow chart
Untuk mengetahui keakuratan kerja alat ukur jarak ultrasonik ini dengan membandingkannya dengan alat ukur acuan yaitu mistar. Pengukuran jarak ini dilakukan dengan menvariasikan objek pengukuran yaitu berupa kayu, kapas dan air.

a. Pengukuran jarak ke objek berupa kayu

Kayu yang digunakan disini adalah kayu surian berbentuk persegi ukuran sisinya $0.5 \mathrm{~m}$ dan tebal 0,5 $\mathrm{cm}$. Hasil pengujian karakteristik sensor tehadap objek berupa kayu menunjukkan bahwa pengukuran jarak antara alat ukur acuan dengan sensor ultrasonik cukup linier. Ini membuktikan bahwa sensor ultrasonik tidak menembus medium yang rapat. Hasil pengujian menunjukkan karakteristik sensor antara pembacaan hasil pengkuran jarak dengan menggunakan sensor ultrasonik hampir sama dengan alat ukur acuan ini terlihat dari gambar 5 . Hal ini dibuktikan dengan derajat korelasi linier dan koefisien determinasi $\mathrm{R}^{2}$ yang cukup baik yaitu mendekati 1 .

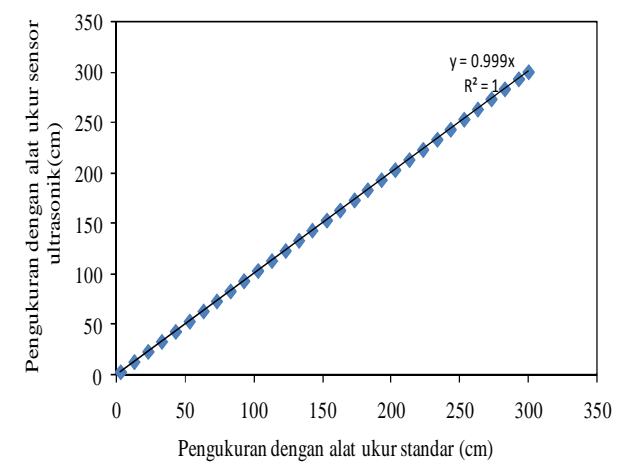

Gambar 5. Karakteristik sensor terhadap objek berupa kayu

Kesalahan relatif maksimum pengukuran jarak dengan sensor ultrasonik untuk objek berupa kayu adalah $3.3 \%$ ini diperoleh untuk jarak $\leq 3 \mathrm{~cm}$. Jarak yang sangat dekat 
terhadap objek yang diukur meyebabkan sensor kurang sensitif. Kesalahan relatif terhadap masingmasing pengukuran dapat dilihat pada Gambar 6.

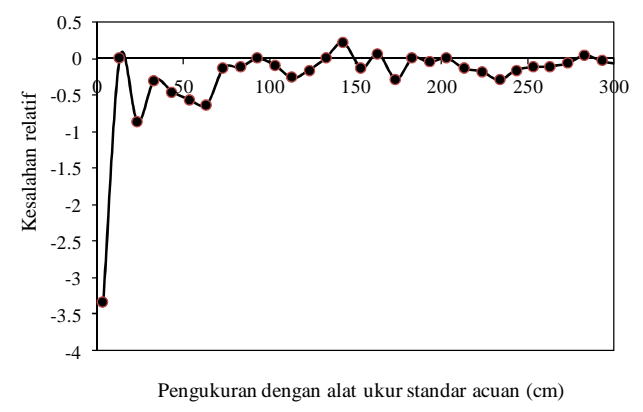

Gambar 6. Kesalahan relatif alat ukur jarak dengan objek berupa kayu

b. Pengukuran jarak ke objek berupa kapas

Kapas yang digunakan sebagai objek pengukuran dalam pengukuran ini berukuran $15 \mathrm{~cm}$ x $10 \mathrm{~cm}$ dengan ketebalan $10 \mathrm{~cm}$. Hasil pengukuran jarak antara alat ukur acuan dan pengukuran dengan sensor ultrasonik terdapat sedikit perbedaan, pada umumnya hasil pembacaan dengan sensor ultasonik lebih panjang dari pada pembacaan dengan alat ukur acuan, ini disebabkan karena sensor ultrasonik dapar menembus kapas sampai ketebalan 1-4 cm. Karakteristik sensor terhadap objek berupa kapas dapat dilihat pada gambar 7.

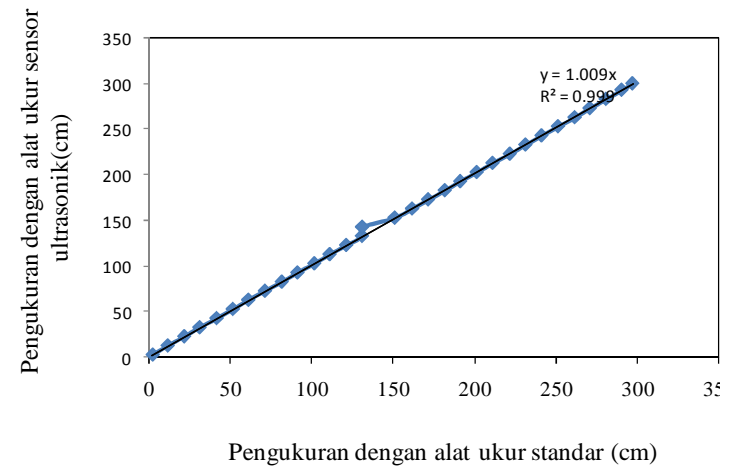

Gambar 7. Karakteristik sensor terhadap objek berupa kapas

Dari gambar 8 persen kesalahan relatif maksimum pengukuran jarak dengan sensor PNG))) ultrasonik untuk objek berupa kapas adalah 28 $\%$. Secara keseluruhan persentase kesalahan relatif besar ini disebabkan karena gelombang ultrasonic yang dikirim oleh sensor dapat menembus medium yang renggang. Untuk pengukuran jarak antara $3 \mathrm{~cm}$ sampai $50 \mathrm{~cm}$ persen kesalaha relatif cukup besar karena untuk jarak yang dekat gelombang yang dipancarkan sensor dapat menembus kapas sebaiknya kapas yang digunakan dipadatkan volumenya. Untuk jarak $51 \mathrm{~cm}-300$ $\mathrm{cm}$ persen kesalahan relatif hampir sama.

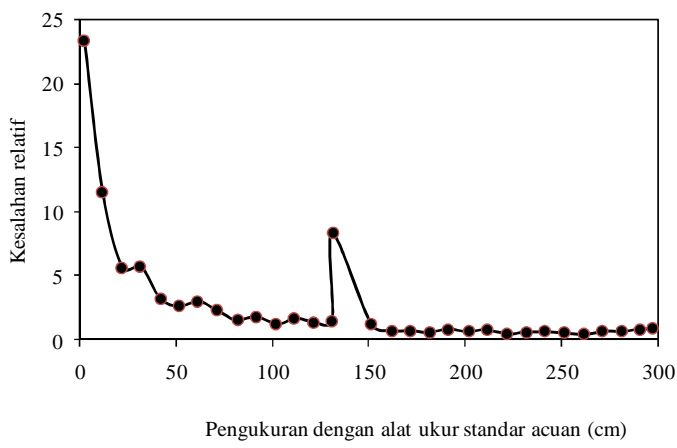

Gambar 8. Kesalahan relatif alat ukur jarak dengan objek berupa kapas

c. Pengukuran jarak ke objek berupa air

Hasil pengukuran jarak permukaan air hampir sama dengan hasil pembacaan dengan alat ukur acuan. Ini terlihat dari gambar 9. Hal ini dibuktikan dengan derajat korelasi linier dan koefisien determinasi $\mathrm{R}^{2}$ yang cukup baik yaitu mendekati 1Untuk kesalahan relatif maksimum pengukuran jarak dengan sensor PING))) ulrasonik untuk objek berupa 
air adalah $1,88 \%$ dan kesalahan relatif rata-rata adalah $0,21 \%$ ini terlihat pada gambar 10 .

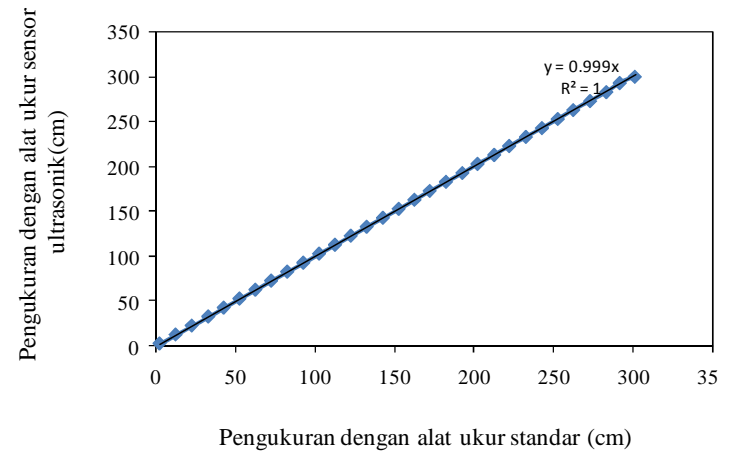

Gambar

9. Karakteristik sensor terhadap permukaan air

Dari hasil pengujian sensor untuk jarak $3 \mathrm{~cm}$ sampai $30 \mathrm{~cm}$ sensor ultrasonik dapat menembus permukaan air sampai kedalaman 0,6 $\mathrm{cm}$ sedangkan pada jarak $50 \mathrm{~cm}$ hingga $3 \mathrm{~m}$ alat ukur jarak ini tidak dapat menembus permukaan air.

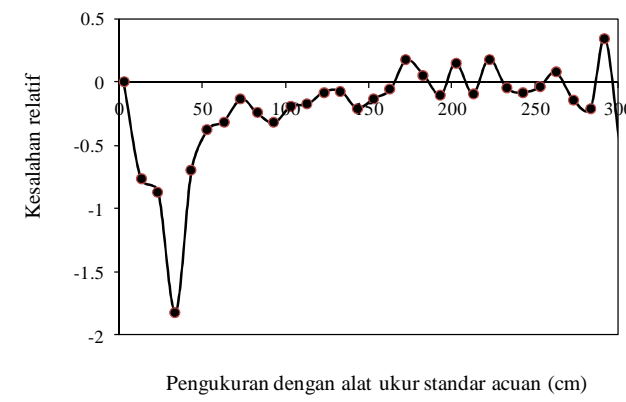

Gambar10. Kesalahan relatif alat ukur jarak dengan objek berupa air

\section{KESIMPULAN}

Dari rancang bangun alat ukuur jarak menggunakan sensor Ping))) ultrasonik berbasis mikrokontroler AT89S51 rentang jarak pengukuran yang dapat dilakukan antara $3 \mathrm{~cm}$ sampai $3 \mathrm{~m}$, dengan resolusi jarak 1 $\mathrm{cm}$. Jika pengukuran dilakukan pada medium yang renggang diperoleh kesalahan relative pembacaan alat ukur yang besar. Alat ukur jarak menggunakan sensor ultrasonic sesuai digunakan untuk mengukur jarak ke medium yang rapat.

\section{DAFTAR PUSTAKA}

Nalwan, Paulus Andi. "Teknik Antarmuka dan Pemrograman Mikrokontroler AT89C51”. PT Elex Media Komputindo: Jakarta. 2003.

Putra, Agfianto Eko. "Belajar Mikrokontroler

AT89C51/52/55”. Gava Media. Yogyakarta. 2003.

www. Paralak.com. "Ping)))

Ultrasonic Distance Sensor (\#28015)". Hal 1-9. 2013

Sigit, R. "Robotika, Sensor dan Aktuator. Graha Ilmu, Yogyakarta. 2007. 